\title{
Veno-venous extracorporeal blood phototherapy increases the rate of carbon monoxide (CO) elimination in $\mathrm{CO}$-poisoned pigs
}

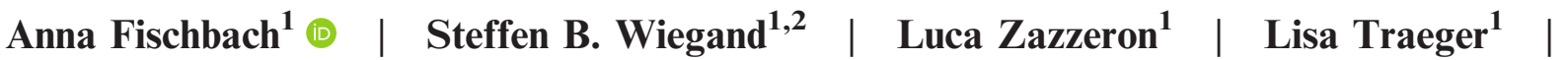 \\ Raffaele di Fenza $^{1}$ | Aranya Bagchi $^{1}$ | William A. Farinelli ${ }^{3}$ | Walfre Franco ${ }^{4}$ (i) | \\ Sandeep Korupolu $^{3}$ | Jutta Arens ${ }^{5}$ | Luigi Grassi $^{1}$ | Francesco Zadek ${ }^{1}$ | \\ Donald B. Bloch $^{1,6}$ | R. Rox Anderson ${ }^{3}$ | Warren M. Zapol ${ }^{1}$
}

\begin{abstract}
${ }^{1}$ Anesthesia Center for Critical Care Research of the Department of Anesthesia, Critical Care and Pain Medicine, Massachusetts General Hospital, Harvard Medical School, Boston, Massachusetts, USA

${ }^{2}$ Department of Anesthesiology, University Hospital, LMU Munich, Munich, Germany

${ }^{3}$ Department of Dermatology, Massachusetts General Hospital and Harvard Medical School, Wellman Center for Photomedicine, Boston, Massachusetts, USA

${ }^{4}$ Department of Biomedical Engineering, University of Massachusetts, Lowell,

Massachusetts, USA

${ }^{5}$ Department of Biomechanical Engineering, Faculty of Engineering Technology, University of Twente, Twente, The Netherlands

${ }^{6}$ Division of Rheumatology, Allergy, and Immunology, Department of Medicine, Massachusetts General Hospital, Harvard Medical School, Boston, Massachusetts, USA
\end{abstract}

\section{Correspondence}

Warren M. Zapol, Anesthesia Center for Critical Care Research of the Department of Anesthesia, Critical Care and Pain Medicine, Massachusetts General Hospital, Harvard Medical School, Boston, MA, USA.

Email:wzapol@mgh.harvard.edu

Funding information

Deutsche Forschungsgemeinschaft, Grant/Award Numbers: FI 2429/1-1, TR 1642/ 1-1, WI 5162/2-1; Luisa Hunnewell and Larry Newman, Grant/Award Number: not available

\begin{abstract}
Background and objectives: Carbon monoxide $(\mathrm{CO})$ inhalation is the leading cause of poison-related deaths in the United States. CO binds to hemoglobin ( $\mathrm{Hb})$, displaces oxygen, and reduces oxygen delivery to tissues. The optimal treatment for $\mathrm{CO}$ poisoning in patients with normal lung function is the administration of hyperbaric oxygen (HBO). However, hyperbaric chambers are only available in medical centers with specialized equipment, resulting in delayed therapy. Visible light dissociates $\mathrm{CO}$ from $\mathrm{Hb}$ with minimal effect on oxygen binding. In a previous study, we combined a membrane oxygenator with phototherapy at $623 \mathrm{~nm}$ to produce a "mini" photo-ECMO (extracorporeal membrane oxygenation) device, which improved $\mathrm{CO}$ elimination and survival in $\mathrm{CO}$-poisoned rats. The objective of this study was to develop a larger photo-ECMO device ("maxi" photo-ECMO) and to test its ability to remove $\mathrm{CO}$ from a porcine model of $\mathrm{CO}$ poisoning.

Study design/materials and methods: The "maxi" photo-ECMO device and the photo-ECMO system (six maxi photo-ECMO devices assembled in parallel), were tested in an in vitro circuit of $\mathrm{CO}$ poisoning. To assess the ability of the photoECMO device and the photo-ECMO system to remove $\mathrm{CO}$ from $\mathrm{CO}$-poisoned blood in vitro, the half-life of $\mathrm{COHb}\left(\mathrm{COHb}-t_{1 / 2}\right)$, as well as the percent $\mathrm{COHb}$ reduction in a single blood pass through the device, were assessed. In the in vivo studies, we assessed the $\mathrm{COHb}-t_{1 / 2}$ in a CO-poisoned pig under three conditions: (1) While the pig breathed $100 \%$ oxygen through the endotracheal tube; (2) while the pig was connected to the photo-ECMO system with no light exposure; and (3) while the pig was connected to the photo-ECMO system, which was exposed to red light.

Results: The photo-ECMO device was able to fully oxygenate the blood after a single pass through the device. Compared to ventilation with 100\% oxygen alone, illumination with red light together with $100 \%$ oxygen was twice as efficient in removing $\mathrm{CO}$ from blood. Changes in gas flow rates did not alter $\mathrm{CO}$ elimination in one pass through the device. Increases in irradiance up to $214 \mathrm{~mW} / \mathrm{cm}^{2}$ were associated with an increased rate of $\mathrm{CO}$ elimination. The photo-ECMO device was effective over a range of blood flow rates and with higher blood flow rates, more $\mathrm{CO}$ was eliminated. A photo-ECMO system composed of six photo-ECMO devices removed $\mathrm{CO}$ faster from $\mathrm{CO}$-poisoned blood than a single photo-ECMO device. In a CO-poisoned pig, the photo-ECMO system increased the rate of CO elimination without significantly increasing the animal's body temperature or causing hemodynamic instability.
\end{abstract}


Conclusion: In this study, we developed a photo-ECMO system and demonstrated its ability to remove $\mathrm{CO}$ from $\mathrm{CO}-$ poisoned $45-\mathrm{kg}$ pigs. Technical modifications of the photo-ECMO system, including the development of a compact, portable device, will permit treatment of patients with $\mathrm{CO}$ poisoning at the scene of their poisoning, during transit to a local emergency room, and in hospitals that lack HBO facilities.

\section{K E Y W O R D S}

blood phototherapy, carbon monoxide, carbon monoxide poisoning, extracorporeal membrane oxygenation, photodissociation

\section{INTRODUCTION}

Carbon monoxide (CO) inhalation and poisoning leads to more than 50,000 visits to emergency departments in the United States each year ${ }^{1}$ and is the main cause of poisoning-related deaths. ${ }^{2}$ The mortality rate from $\mathrm{CO}$ poisoning is $1 \%-3 \%{ }^{3,4}$ and the rate of morbidity is nearly $40 \%{ }^{5}$ Patients who survive CO poisoning often suffer from neurologic symptoms, including cognitive dysfunction, motor deficits, depression, and anxiety. ${ }^{6}$ Cardiac sequelae after $\mathrm{CO}$ poisoning include myocardial infarction, ${ }^{7}$ reduced left ventricular function, ${ }^{8}$ and arrhythmias. ${ }^{9}$ The neurologic and cardiac sequelae of $\mathrm{CO}$ poisoning increase morbidity and mortality. ${ }^{10}$ The economic burden of $\mathrm{CO}$ poisoning in the United States, if one considers both hospital costs and lost earnings, is approximately 1.3 billion dollars each year. ${ }^{11}$

The toxicity associated with inhalation of $\mathrm{CO}$ is caused by impairment of oxygen $\left(\mathrm{O}_{2}\right)$ delivery to and inhibition of ATP generation in mitochondria. ${ }^{12} \mathrm{He}-$ moglobin $(\mathrm{Hb})$ has a 250 -fold higher affinity for $\mathrm{CO}$ than for oxygen. ${ }^{13}$ Carboxyhemoglobin $(\mathrm{COHb})$ reduces the oxygen-carrying capacity of blood, resulting in tissue hypoxia. ${ }^{14}$ The main goal of treatment for $\mathrm{CO}$ poisoning is, therefore, to remove $\mathrm{CO}$ from the body as quickly as possible. The efficacy of $\mathrm{CO}$ removal can be measured in terms of the half-life of $\mathrm{COHb}\left(\mathrm{COHb}-t_{1 / 2}\right)$, which represents the time needed to remove $50 \%$ of the $\mathrm{COHb}$ from blood. The standard treatment for $\mathrm{CO}$ poisoning is to breathe either normobaric or hyperbaric $100 \% \mathrm{O}_{2} .{ }^{15,16} \mathrm{By}$ increasing the partial pressure of $\mathrm{O}_{2}$, $\mathrm{CO}$ is displaced from $\mathrm{Hb}$ and exhaled through the lungs. When a patient with $\mathrm{CO}$ poisoning breathes air, the COHb- $t_{1 / 2}$ is $4-5 \mathrm{~h}^{17}$ Breathing $100 \% \quad \mathrm{O}_{2}$ reduces $\mathrm{COHb}-t_{1 / 2}$ to $1.5-2 \mathrm{~h} .{ }^{18}$ Hyperbaric oxygen $(\mathrm{HBO}) \mathrm{can}$ further reduce $\mathrm{COHb}-t_{1 / 2}$ to $30 \mathrm{~min} .{ }^{19}$ However, oxygen therapy for the treatment of $\mathrm{CO}$ poisoning has important limitations. Because HBO chambers are only available in medical centers with specialized equipment, this therapy is delayed by the time needed for patient transport. In addition, when $\mathrm{CO}$ poisoning is associated with lung injury, which can be produced by inhalation of smoke or other chemicals, ${ }^{20,21}$ oxygen therapy to remove $\mathrm{CO}$ from the lungs becomes less effective due to limited gas exchange.
Haldane and Smith $^{22}$ reported in 1896 that visible light dissociates $\mathrm{CO}$ from $\mathrm{COHb}$ without altering the ability of $\mathrm{Hb}$ to bind $\mathrm{O}_{2}$. In a recent study, we reported the development of an extracorporeal veno-venous membrane oxygenator with optimized characteristics to facilitate exposure of blood to visible light. ${ }^{23} \mathrm{We}$ tested this "mini" photo-ECMO (extracorporeal membrane oxygenation) device in a rat model of $\mathrm{CO}$ poisoning, with and without concomitant lung injury, and observed that the device significantly increased the rate of $\mathrm{CO}$ removal from blood and improved the survival rate of CO-poisoned rats. However, a larger ("maxi" photo-ECMO) device is required before photo-ECMO can be considered a potential option for treating $\mathrm{CO}$ poisoning in humans. In this study, we report the development and characterization of a maxi photo-ECMO device and show that the device can efficiently remove $\mathrm{CO}$ from $\mathrm{CO}$-poisoned blood in vitro. We further demonstrate that six maxi photo-ECMO devices, combined within a single "photo-ECMO system," increases the rate of $\mathrm{CO}$ elimination in a porcine model of $\mathrm{CO}$ poisoning.

\section{MATERIALS AND METHODS}

\section{Study design}

The aim of this study was to assess the feasibility and efficacy of extracorporeal blood phototherapy in a large animal model of CO poisoning. We developed a membrane oxygenator suitable for blood phototherapy in a large animal and combined six of these devices to a photo-ECMO system. We tested the device and the photo-ECMO system in an in vitro circuit of $\mathrm{CO}$ poisoning. We studied the effect of extracorporeal blood phototherapy in a nonlethal model of $\mathrm{CO}$ poisoning in $45-\mathrm{kg}$ pigs. All in vitro experiments were at least repeated four times. All animal studies were performed using protocols approved by the Institutional Animal Care and Use Committee at our institution and in accordance with National Institutes of Health guidelines. The sample size was decided on the basis of pilot experiments to ensure a power of $80 \%$ and a significance of $5 \%$. The investigators were not blinded to experiments. All data were included (no outlier values were excluded). 


\section{Construction of a "maxi" photo-ECMO device}

To construct a "maxi" photo-ECMO device, 15 polypropylene hollow fiber membrane mats, each $160 \mathrm{~mm}$ by $160 \mathrm{~mm}$, with a fiber density of 20 fibers $/ 10 \mathrm{~mm}$ (Oxyphan $50 / 280 ; 3 \mathrm{M}$ ), were placed on top of each other, with the hollow fibers of each layer rotated $90^{\circ}$ relative to the layer below to maximize gas exchange area. Silicone rubber adhesive (Elastosil RT625; Wacker) was used to hold the membrane bundle together and the membranes were enclosed in a clear plexiglass case with four openings for blood and gas inlets and outlets. The device consists of three sealed compartments: One compartment with blood flowing around the membrane tubules and two individual compartments (separated by a silicone barrier) for gas inflow and outflow (Figure 1A and S1).

\section{Assembling the photo-ECMO system}

The photo-ECMO system consists of six "maxi" photoECMO devices arranged in parallel (Figures 6A and S4). A blood inflow port with six openings for blood entering the photo-ECMO system and a blood outflow port with six openings for blood exiting the photo-ECMO system was built to ensure equal blood flow distribution to all six
photo-ECMO devices. The blood in- and outflow branches consist of seven Y-pieces connected to silicone tubing. Compared to a single photo-ECMO device, the gas exchange and total surface area for incident light increased from 0.6 to $3.6 \mathrm{~m}^{2}$ and from 450 to $2700 \mathrm{~cm}^{2}$, respectively. The blood compartment volume increased from 60 to $360 \mathrm{ml}$. We used 240 LEDs in the photoECMO system with a total light power of 578 Watts.

\section{In vitro assessment of $\mathrm{COHb}-t_{1 / 2}$ using the photo-ECMO device and the photo-ECMO system}

The first in vitro circuit consisted of one open reservoir, a peristaltic pump (NE-9004; New Era Pump Systems Inc.), silicone rubber tubing, the maxi photo-ECMO device, or the photo-ECMO system (Figure 1B). $300 \mathrm{ml}$ (for preliminary testing) or $1 \mathrm{~L}$ of human whole blood from different, healthy volunteers (Research Blood Components), at a $\mathrm{Hb}$ concentration of $9.6 \pm 0.3 \mathrm{~g} / \mathrm{dl}$ (with $300 \mathrm{ml}$ of blood) and $10.0 \pm 1.4 \mathrm{~g} / \mathrm{dl}$ (with $1 \mathrm{~L}$ of blood), anticoagulated with CPDA-1, was saturated with $\mathrm{CO}$ by circulating the blood through the device while it was ventilated with $2 \% \mathrm{CO}$ diluted in air. A Level 1 hotline (Smiths Medical) was used to maintain the blood
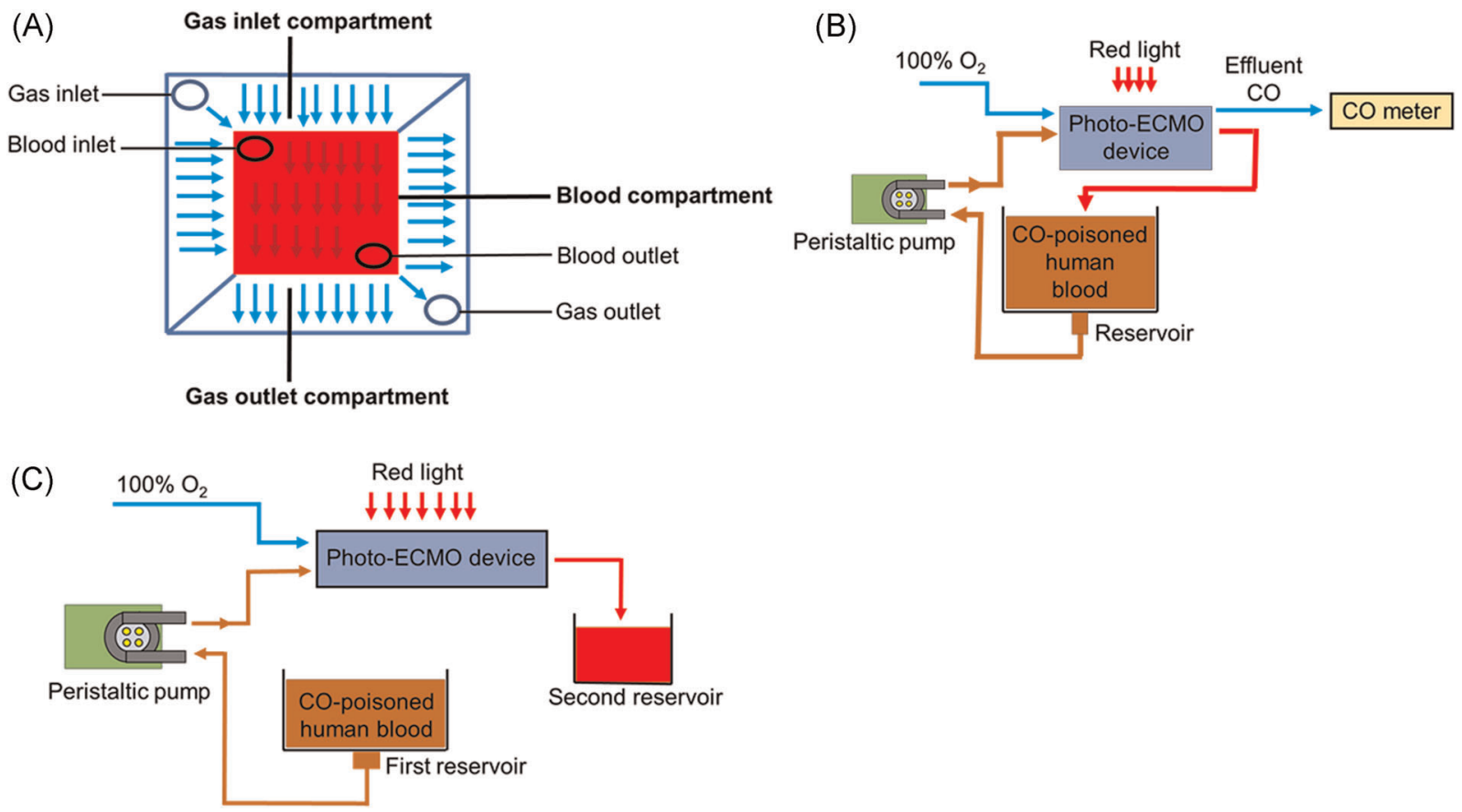

FIG URE 1 Depiction of the photo-ECMO device and in vitro models to test the ability of the photo-ECMO device to eliminate CO from blood. (A) Design of the photo-ECMO device. The photo-ECMO device consists of a central blood compartment and two peripheral gas compartments (gas inlet and outlet). Oxygen entered the gas inlet compartment to pass through the hollow membrane fibers to reach the gas outlet compartment. Meanwhile, CO-poisoned blood crossed the blood compartment and flows around the membrane fibers, while being illuminated by red light at $623 \mathrm{~nm}$ from both sides of the device. (B) Human whole blood circulated from a reservoir through a peristaltic pump to the photo-ECMO device and returned to the reservoir (assessment of $\mathrm{COHb}$ half-life). The $\mathrm{COHb}$ half-life is the most relevant, clinical parameter as it provides information on the time needed to remove $\mathrm{CO}$ from blood. (C) A peristaltic pump was used to transfer human blood from the first reservoir through the photo-ECMO device into a second reservoir (assessment of percent $\mathrm{COHb}$ reduction). $\mathrm{COHb}$, carboxyhemoglobin; ECMO, extracorporeal membrane oxygenation 
temperature at $37^{\circ} \mathrm{C}$. For experimental simplicity, blood was poisoned to a $\mathrm{COHb}$ concentration of $90 \%$. After $\mathrm{Hb}$ was $90 \%$ saturated with $\mathrm{CO}$, which was confirmed by blood gas analysis (ABL800 FLEX; Radiometer), $300 \mathrm{ml}$ of reservoir blood passed through the photo-ECMO device at various blood flows $(80,160$, and $240 \mathrm{ml} / \mathrm{min}$ ) while the device was ventilated with $100 \% \mathrm{O}_{2}$ at various gas flow rates $(1,1.6$, and $2.4 \mathrm{~L} / \mathrm{min})(N=4$ per group). When the blood reservoir contained $1 \mathrm{~L}$ of blood, blood passed the photo-ECMO device at a blood flow rate of $92 \mathrm{ml} / \mathrm{min}$ and the photo-ECMO system at a blood flow rate of $550 \mathrm{ml} / \mathrm{min}$. The photo-ECMO device or -system was either exposed to LEDs emitting light at a wavelength of $623 \mathrm{~nm}$ and an irradiance of $214 \mathrm{~mW} / \mathrm{cm}^{2}$ (power per unit area of light reaching the surface of the membrane oxygenator), or no light (control) $(N=4$ per group). The $\mathrm{COHb}$ concentration changes over time were used to calculate the COHb- $t_{1 / 2}$ of the blood volume in the reservoir. During the treatment period, the concentration of $\mathrm{CO}$ removed by the photo-ECMO device (effluent $\mathrm{CO}$ ) was measured using a $\mathrm{CO}$ gas analyzer (MSA Altair 2X; MSA Safety Inc.). COHb- $t_{1 / 2}$ was assessed to determine the ability of the photo-ECMO device to remove $\mathrm{CO}$ from reservoir blood.

\section{Assessment of percent $\mathrm{COHb}$ reduction and temperature increase with a single pass}

The second in vitro circuit consisted of two open reservoirs, a peristaltic pump, silicone rubber tubing, and the photo-ECMO device (Figure 1C). CO-poisoned human blood at a $\mathrm{Hb}$ concentration of $10.6 \pm 0.5 \mathrm{~g} / \mathrm{dl}$ (effect of irradiance on CO removal) and $10.1 \pm 0.3 \mathrm{~g} / \mathrm{dl}$ (effect of different gas flow rates on $\mathrm{CO}$ removal) was pumped at a blood flow rate of $80 \mathrm{ml} / \mathrm{min}$ from the first reservoir through the peristaltic pump, to the photo-ECMO device, and to the second reservoir. While blood passed through the photo-ECMO device, it was either ventilated with $100 \% \mathrm{O}_{2}$ (control) at a gas flow rate of $1 \mathrm{~L} / \mathrm{min}$ or ventilated with $100 \% \mathrm{O}_{2}$ at the same gas flow rate while being illuminated with red light at a wavelength of $623 \mathrm{~nm}$. Blood samples were taken from the first reservoir and, after the blood passed through the photoECMO device, from the second reservoir. Four different irradiances $\left(36,101,160\right.$, and $\left.214 \mathrm{~mW} / \mathrm{cm}^{2}\right)$ and four different gas flow rates were tested (1, 1.6, 2.4, and 3.2 L/ $\mathrm{min}$ ). To assess the temperature increase on a single pass through the photo-ECMO device, the blood temperature was measured as blood entered and exited the device.

\section{Animals}

This study was approved by Institutional Animal Care and Use Committee (IACUC) at Massachusetts General Hospital, Boston, MA. Four 3 months old, female
Yorkshire pigs with an average weight of $45.3 \pm 1.3 \mathrm{~kg}$ were studied. The $\mathrm{Hb}$ concentration in these pigs was $9.1 \pm 0.3 \mathrm{~g} / \mathrm{dl}$. Animals were acclimatized $12 \mathrm{~h}$ before the experiment. Premedication with atropine $(0.04 \mathrm{mg} / \mathrm{kg})$, xylazine $(2.2 \mathrm{mg} / \mathrm{kg})$, and telazol $(4.4 \mathrm{mg} / \mathrm{kg})$ was used. Anesthesia was maintained with a continuous infusion of propofol $(10 \mathrm{mg} / \mathrm{kg} / \mathrm{h})$ and fentanyl $(3 \mu \mathrm{g} / \mathrm{kg} / \mathrm{h})$. Pigs were intubated with a 7.0-mm cuffed endotracheal tube and connected to a ventilator (Ohmeda 7000). Respiratory rate was adjusted to maintain $\mathrm{CO}_{2}$ levels $(35-45 \mathrm{mmHg})$. The $\mathrm{FiO}_{2}$ during $\mathrm{CO}$ poisoning was 0.21 and during treatment 1.0. PEEP was fixed at $5 \mathrm{~cm} \mathrm{H}_{2} \mathrm{O}$. Muscle relaxation was provided with a continuous infusion of pancuronium $(0.06 \mathrm{mg} / \mathrm{kg} / \mathrm{h})$. For continuous anesthesia, a 24 Gauge catheter (BBraun) was placed in an ear vein. An 18 Gauge catheter (Teleflex) was inserted into the right carotid artery for blood sampling and pressure measurement. Body temperature was continuously measured with a rectal temperature probe.

\section{Experimental protocol}

After surgical preparation, pigs were poisoned while breathing $3000 \mathrm{ppm} \mathrm{CO}$ through the endotracheal tube until a $\mathrm{COHb}$ level of $50 \%$ was reached. All animals were first treated by breathing $100 \% \mathrm{O}_{2}$ through the endotracheal tube (control). Thereafter, pigs were re-poisoned with $3000 \mathrm{ppm}$ $\mathrm{CO}$ until the previous $\mathrm{COHb}$ level was reached $(\mathrm{COHb}$ of $50 \%$, CO poisoning 2). During that phase, animals were connected to the photo-ECMO system. $50 \%$ of all pigs were first treated with the photo-ECMO system ventilated with $100 \% \mathrm{O}_{2}$ without additional exposure of the device to light (Treatment 2). After the last CO-poisoning phase (CO poisoning 3), these pigs were then treated with the photoECMO system ventilated with $100 \% \mathrm{O}_{2}$ and additional exposure of the devices to light (Treatment 3). The other 50\% of pigs were first treated with the photo-ECMO device ventilated with $100 \% \mathrm{O}_{2}$ with additional light exposure. After the third CO-poisoning phase, they were then treated with the photo-ECMO system which was ventilated with $100 \% \mathrm{O}_{2}$ without additional exposure of the devices to light.

\section{Veno-venous extracorporeal circuit in pigs}

CO-poisoned blood was drained from the animal through a 12 French cannula (Medtronic) placed in the right external jugular vein. The blood circulated through tubing with an internal diameter of $1 / 8$ inches (Masterflex) and at a blood flow rate of $550 \mathrm{ml} / \mathrm{min}$ through a peristaltic pump (NE-9004; New Era Pump Systems Inc.) to the photo-ECMO system and returned to the animal through a 12 French cannula (Medtronic) inserted in the left external jugular vein. The extracorporeal circuit (photo-ECMO system and tubing) was primed with a sterile ringer's lactate solution. To avoid blood clotting, 
three units of heparin per $\mathrm{ml}$ ringer lactate were added to the priming solution. All pigs received $300 \mathrm{U} / \mathrm{kg}$ of heparin after cannulation. ACT (activated clotting time) samples were drawn periodically. Additional heparin was given to maintain an ACT of 400-450 s.

\section{Measurement and calculations}

The hemoglobin concentration $(\mathrm{Hb})$, oxygen saturation $\left(\mathrm{SatO}_{2}\right)$, and the fraction of $\mathrm{COHb}$ and partial pressure of oxygen $\left(\mathrm{PO}_{2}\right)$ in blood samples were measured using a blood gas analyzer. The oxygen transfer of the photoECMO device was calculated as follows:

$$
\begin{aligned}
& \text { Oxygen transfer normalized to } \\
& 1 \mathrm{~L} / \mathrm{min} \text { blood flow }\left(\mathrm{ml}_{\mathrm{O}_{2}} / \mathrm{L}_{\text {blood }}\right) \\
& =\left[\left(\mathrm{c}_{\text {post }}\left(\mathrm{ml}_{\mathrm{O}_{2}} / \mathrm{dl}_{\text {blood }}\right)-\mathrm{c}_{\text {pre }}\left(\mathrm{ml}_{\mathrm{O}_{2}} / \mathrm{dl}_{\text {blood }}\right)\right) \times 10 \mathrm{dl} / \mathrm{L}\right] \\
& \times Q_{\text {blood }}\left(\mathrm{L}_{\text {blood }} / \mathrm{min}\right) / 1 \mathrm{~L}_{\text {blood }} / \mathrm{min} \text {, whereas } \\
& c_{\text {pre }}\left(\mathrm{ml}_{\mathrm{O}_{2}} / \mathrm{dl}_{\text {blood }}\right)=\left[\left(\operatorname{SatO}_{2 \text { pre }}(\%) / 100\right)\right. \\
& \left.\times \mathrm{Hb}\left(\mathrm{g} / \mathrm{dl}_{\text {blood }}\right) \times 1.34 \mathrm{ml}_{\mathrm{O}_{2}} / \mathrm{g}_{\mathrm{Hb}}\right] \\
& +\left[0.003 \mathrm{ml}_{\mathrm{O}_{2}} / \mathrm{mmHg}\right. \\
& \left./ \mathrm{dl}_{\text {blood }} \times P \mathrm{O}_{2 \text { pre }}(\mathrm{mmHg})\right] \\
& c_{\text {post }}\left(\mathrm{ml}_{\mathrm{O}_{2}} / \mathrm{dl}_{\text {blood }}\right)=\left[\left(\mathrm{SatO}_{2 \text { post }}(\%) / 100\right)\right. \\
& \left.\times \mathrm{Hb}\left(\mathrm{g} / \mathrm{dl}_{\text {blood }}\right) \times 1.34 \mathrm{ml}_{\mathrm{O}_{2}} / \mathrm{g}_{\mathrm{Hb}}\right] \\
& +\left[0.003 \mathrm{ml}_{\mathrm{O}_{2}} / \mathrm{mmHg} / \mathrm{dl}_{\text {blood }}\right. \\
& \left.\times \mathrm{PO}_{2 \text { post }}(\mathrm{mmHg})\right] \text {. }
\end{aligned}
$$

$Q_{\text {blood }}$ is the blood flow rate, $c$ is the oxygen content, whereas $c_{\text {pre }}$ is the oxygen content of blood entering the device and $c_{\text {post }}$ is the oxygen content of blood exiting the device. $0.003 \mathrm{ml}_{\mathrm{O}_{2}} / \mathrm{mmHg} / \mathrm{dl}_{\text {blood }}$ is the solubility coefficient of oxygen in blood and $1.34 \mathrm{ml}_{\mathrm{O}_{2}} / \mathrm{g}_{\mathrm{Hb}}$ is the oxygen-binding capacity of $\mathrm{Hb}$. The $\mathrm{Hb}$ concentration was $10.5 \pm 0.3 \mathrm{~g} / \mathrm{dl}$.

The ability of the photo-EMCO device to remove CO from blood was determined by measuring the level of blood $\mathrm{COHb}$ before and after a single transit through the device using the following equation:

$$
\mathrm{COHb} \text { reduction }=\frac{\mathrm{COHb}_{\text {pre }}-\mathrm{COHb}_{\text {post }}}{\mathrm{COHb}_{\text {pre }}} \times 100 \text {. }
$$

The $\mathrm{Hb}$ concentration in these studies was $10.5 \pm 0.3 \mathrm{~g} / \mathrm{dl}$ (effect of irradiance on $\mathrm{CO}$ removal) and $10.1 \pm 0.3 \mathrm{~g} / \mathrm{dl}$ (effect of different gas flow rates on $\mathrm{CO}$ removal).

To determine the COHb- $t_{1 / 2}$, the percentage of $\mathrm{Hb}$ that was in the form of $\mathrm{COHb}$ was measured at four different time points $(t=0,5,10$, and $15 \mathrm{~min}$ for the in vitro experiments and $t=0,10,20$, and $30 \mathrm{~min}$ for the in vivo experiments) after the beginning of treatment. An exponential decay equation $\left(y=\mathrm{e}^{-k x}\right)$ was generated. The half-life of $\mathrm{COHb}$ was calculated as $\mathrm{COHb}-t_{1 / 2}=\ln$ (2) $\mathrm{k}^{-1}$. During the treatment period, the concentration of exhaled CO from the animal and the $\mathrm{CO}$ eliminated from the photo-EMCO device or the photo-ECMO system (effluent) were measured using a $\mathrm{CO}$ gas analyzer (MSA Altair 2X; MSA Safety Inc.). The quantity of exhaled and effluent $\mathrm{CO}$ was calculated as the product between the concentration of $\mathrm{CO}$ and the sweep gas flow. The $\mathrm{Hb}$ concentration in these studies was $9.6 \pm 0.3 \mathrm{~g} / \mathrm{dl}$ (experiments with a blood volume of $300 \mathrm{ml}$ ) and $10.0 \pm 1.4 \mathrm{~g} / \mathrm{dl}$ (experiments with a blood volume of $1 \mathrm{~L}$ ).

\section{Assessment of hemolysis}

To determine the amount of free $\mathrm{Hb}(\mathrm{mg} / \mathrm{dl})$ in the porcine blood plasma, blood samples were taken every 30 min from the initiation of the ECMO circuit. Plasma $\mathrm{Hb}$ levels were measured using the Hemoglobin Assay Kit (Sigma-Aldrich) according to the manufacturer's instructions. Using a 365 -well plate, $25 \mu 1$ of plasma was added and mixed with $100 \mu \mathrm{l}$ of Trition/ $\mathrm{NaOH}$ reagent. Samples were measured at $400 \mathrm{~nm}$ with a spectrophotometer (SpectraMax M5; Molecular Devices).

\section{Phototherapy}

High power LEDs (LZ4-00R108; Mouser Electronics) with a maximum emitted optical power of $750 \mathrm{~mW}$ at a wavelength of $623 \mathrm{~nm}$ were used (Figure S5). The photo-ECMO device was illuminated using a total of 40 LEDs, with 20 on each side of the device. The photo-ECMO system was illuminated with a total number of 240 LEDs. The LEDs were attached to heat sinks (Mouser electronics). Fans (Dayton) were used to cool the LEDs. A power meter (Thorlabs) was used to measure the irradiance.

\section{Statistical analysis}

Statistical analysis was performed using GraphPad Prism software (v.8.3). Normal distribution was tested by using the Shapiro-Wilk test. Data were analyzed using a twotailed, paired $t$ test, or one-way analysis of variance (ANOVA) with Sidak's multiple comparison test. A paired $t$ test was used to compare oxygen saturation and partial pressure of oxygen in the studies to assess the oxygenating performance of the photo-ECMO device. A one-way ANOVA test was used to assess the effect of different oxygen flow rates on $\mathrm{CO}$ removal. A two-way ANOVA with Tukey's multiple comparison test, for repeated measurements, was used to compare variables over time between groups. Statistical significance was defined as a $p<0.05$. All data are expressed as mean \pm standard deviation (SD) unless specified otherwise. 


\section{RESULTS}

\section{Development of a "maxi" photo-ECMO device}

To construct a "maxi" photo-ECMO device, 15 polypropylene hollow fiber membrane mats (20 fibers/10 mm), each 160/160 mm, were placed on top of each other, with the hollow fibers of each layer rotated $90^{\circ}$ relative to the layer below to maximize gas exchange area. Silicone rubber adhesive was used to hold the membrane bundle together and the membranes were enclosed in a clear plexiglass case with four openings for blood and gas inlets and outlets. The device consists of three sealed compartments: One compartment with blood flowing around the membrane hollow fibers and two individual compartments (separated by a silicone barrier) for gas inflow and outflow (Figures 1A and S1). The photo-ECMO device was illuminated with 40 high-power LEDs at a wavelength of $623 \mathrm{~nm}$ (Figure S2). In a previous study, we demonstrated that, compared to the illumination of the photoECMO device with light at shorter wavelengths, red light at $623 \mathrm{~nm}$ removed more $\mathrm{CO}$ from blood. ${ }^{23}$ Compared to the previously-described mini photo-ECMO device, ${ }^{23}$ the dimensions of the blood compartment (length $\times$ width) and therefore the surface area for light exposure was increased from $60 \times 60 \mathrm{~mm}$ to $150 \times 150 \mathrm{~mm}$ (6-fold). The blood compartment volume was increased from 4 to $60 \mathrm{ml}$ (15-fold). The gas exchange and illumination areas were increased from 0.05 to $0.6 \mathrm{~m}^{2}$ (12-fold) and from 0.0072 to $0.0450 \mathrm{~m}^{2}$ (6-fold), respectively.

\section{The photo-ECMO device efficiently transfers oxygen to blood}

To determine the ability of the photo-ECMO device to oxygenate blood in vitro, the device was first ventilated with pure nitrogen to decrease the blood oxygen sa- turation to $28.6 \% \pm 4.0 \%$. The device was then ventilated with $100 \% \mathrm{O}_{2}$ while blood at a $\mathrm{Hb}$ concentration of $10.5 \pm 0.3 \mathrm{~g} / \mathrm{dl}$ passed through the device at blood flow rates ranging from 80 to $400 \mathrm{ml} / \mathrm{min}$, at a blood temperature of $37^{\circ} \mathrm{C}$. Blood oxygen transfer was calculated from samples taken before and after one passage through the device. At a blood flow rate of 80, 160, 240, 320, and $400 \mathrm{ml} / \mathrm{min}$, the oxygen transfer rate (in $\mathrm{ml}_{\mathrm{O} 2} / \mathrm{L}_{\text {blood flow }}$ ) was $108.3 \pm 4.1,117.8 \pm 2.8,107.7 \pm 4.2,112.6 \pm 4.7$, and $114.2 \pm 5.5 \mathrm{ml} / \mathrm{L}$, respectively (Table S1). The exiting oxygen saturation increased from $28.6 \% \pm 4.0 \%$ (blood inlet) to $96.1 \% \pm 0.8 \%$ (blood outlet) (average oxygen saturation over all blood flow rates tested, $p<0.001$ ). The $\mathrm{PO}_{2}$ concentration increased from $30.0 \pm 7.5 \mathrm{mmHg}$ (blood inlet) to $512.9 \pm 47.0 \mathrm{mmHg}$ (blood outlet) (average $\mathrm{PO}_{2}$ over all blood flow rates tested, $p<0.001$ ). These results show that the photo-ECMO device successfully oxygenates blood in a single pass through the device at blood flow rates ranging from 80 to $400 \mathrm{ml} / \mathrm{min}$.

\section{Elimination of CO from human blood}

An in vitro circuit was used to assess the ability of the maxi photo-ECMO device to remove $\mathrm{CO}$ from $300 \mathrm{ml}$ human whole blood (Figure 1B). When CO-poisoned human blood (COHb level of $90 \%$ ) at a blood temperature of $37^{\circ} \mathrm{C}$ circulated through the device at $80 \mathrm{ml} / \mathrm{min}$, while the device was ventilated with $100 \% \quad \mathrm{O}_{2}$ but not exposed to light (control), the $\mathrm{COHb}-t_{1 / 2}$ was $42.6 \pm 1.5 \mathrm{~min}$ (Figure 2A). Illumination of the device with red light reduced the COHb- $t_{1 / 2}$ by $50 \%$ (red light absent vs. present, $42.6 \pm 1.5 \mathrm{~min}$ vs. $21.4 \pm 1.4 \mathrm{~min}$, $p<0.001)$. The quantity of $\mathrm{CO}$ eliminated by the photoECMO device (effluent $\mathrm{CO}$ ) was greater when the device was exposed to red light and ventilated with $100 \% \mathrm{O}_{2}$, compared to when the device was ventilated with $100 \%$ $\mathrm{O}_{2}$ without light (Figure 2B). These results demonstrate
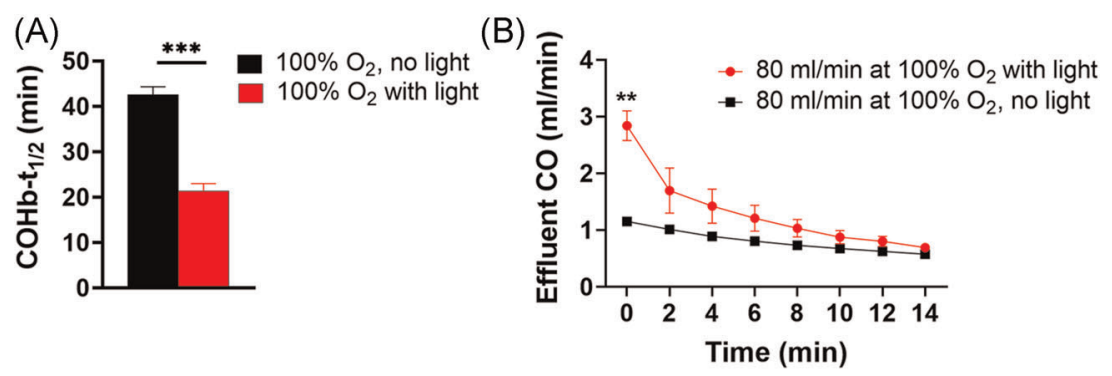

F IGURE 2 In vitro CO elimination from $300 \mathrm{ml}$ of human whole blood with the photo-ECMO device. (A) There was a $50 \%$ decrease in COHb- $t_{1 / 2}$ during in vitro treatment of $300 \mathrm{ml}$ of CO-poisoned blood with $100 \% \mathrm{O}_{2}$ and red phototherapy, compared to oxygen without light $\left(N=4\right.$ per group). Hb concentration was $9.6 \pm 0.3 \mathrm{~g} / \mathrm{dl}$; blood flow was $80 \mathrm{ml} / \mathrm{min}$; gas flow rate was $1 \mathrm{~L} / \mathrm{min}$. Blood temperature was $37^{\circ} \mathrm{C}$. $* * * p<0.001$, two-tailed paired $t$ test. All data represent mean \pm SD. (B) Compared to $100 \% \mathrm{O}_{2}$ alone (control), the combination of $100 \% \mathrm{O}_{2}$ and red light increased the quantity of $\mathrm{CO}$ eliminated from the photo-ECMO device (effluent $\mathrm{CO}$ ). All data represent mean $\pm \mathrm{SD}$. ** $p=0.006$ versus control, two-way analysis of variance. COHb- $t_{1 / 2}$, half-life of carboxyhemoglobin; ECMO, extracorporeal membrane oxygenation 
that the maxi photo-ECMO device increases the rate of $\mathrm{CO}$ elimination from blood in vitro.

\section{Effect of oxygen flow rate on CO removal}

To determine whether higher gas flow rates increase $\mathrm{CO}$ elimination during a single pass through the device, the percent decrease in $\mathrm{COHb}$ concentration at different oxygen flow rates, but a constant blood flow rate was measured (Figure 1C). CO-poisoned human whole blood $(\mathrm{COHb}$ $90 \%)$ at a $\mathrm{Hb}$ concentration of $10.1 \pm 0.3 \mathrm{~g} / \mathrm{dl}$ and at a blood temperature of $37^{\circ} \mathrm{C}$, passed through the photoECMO device at a rate of $80 \mathrm{ml} / \mathrm{min}$, while the device was ventilated with $100 \% \mathrm{O}_{2}$ and exposed to red light at $623 \mathrm{~nm}$. Changing the gas flow rate from 1 to 1.6, 2.4, or to $3.2 \mathrm{~L} / \mathrm{min}$ did not alter the percent reduction in $\mathrm{COHb}$ in a single blood pass through the device $(31.5 \% \pm 0.2 \%$, $32.3 \% \pm 0.6 \%, 32.1 \% \pm 0.2 \%$, and $31.7 \% \pm 0.2 \%, p=$ not significant; Table S2).

\section{Effect of irradiance on $\mathrm{CO}$ removal rate and blood temperature}

The irradiance is the power of light reaching the surface of the device, measured in Watts $/ \mathrm{m}^{2}$. To investigate whether an increase in irradiance increases $\mathrm{CO}$ elimination, we measured the change in the level of $\mathrm{COHb}$ after a single pass through the photo-ECMO device (Figure 1C) at irradiances ranging from 36 to $214 \mathrm{~mW} / \mathrm{cm}^{2}$ (Figure 3 and Table S3). Compared to control (no light), illumination with red light at an irradiance of $36 \mathrm{~mW} / \mathrm{cm}^{2}$ increased the percent $\mathrm{COHb}$ reduction in a single pass through the device from $13.6 \% \pm 0.1 \%$ to $18.7 \% \pm 0.2 \%$. Further increases in irradiance to 101 or $160 \mathrm{~mW} / \mathrm{cm}^{2}$, increased the percent $\mathrm{CO}$ elimination to $22.6 \% \pm 0.5 \%$ and $26.9 \% \pm 0.4 \%$, respectively, $(p<0.001$ for each comparison). Illumination with an irradiance of $214 \mathrm{~mW} / \mathrm{cm}^{2}$ increased CO elimination to $31.5 \% \pm 0.2 \%$

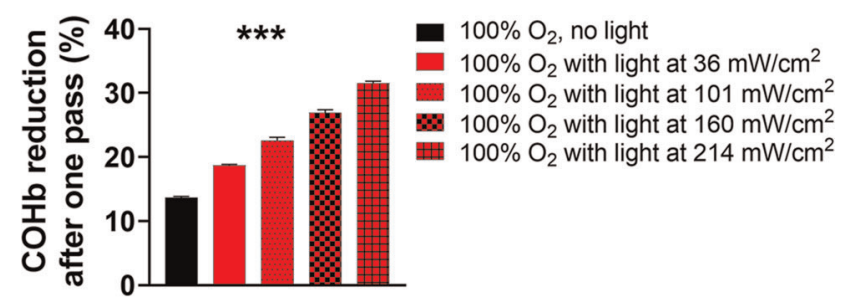

F I G URE 3 The effect of increasing irradiance on $\mathrm{COHb}$ reduction during treatment of human whole blood with the photo-ECMO device with $100 \% \mathrm{O}_{2}$ (control), and red light at $623 \mathrm{~nm}$. Blood flow rate was $80 \mathrm{ml} / \mathrm{min}$; gas flow rate was $1 \mathrm{~L} / \mathrm{min}$ and $\mathrm{Hb}$ concentration was $10.6 \pm 0.5 \mathrm{~g} / \mathrm{dl}$. Blood temperature was $37^{\circ} \mathrm{C}$. All data represent mean \pm SD. $R^{2}=0.9914 .{ }^{* *} p<0.001$ all groups versus control and between groups ( $N=4$ per group), using one-way analysis of variance. $\mathrm{COHb}$, carboxyhemoglobin; ECMO, extracorporeal membrane oxygenation $(p<0.001)$. The changes in temperature of blood passing through the device at blood flow rates of 80,160 , or $240 \mathrm{ml} /$ min, with light at $214 \mathrm{~mW} / \mathrm{cm}^{2}$ were $2.2^{\circ} \mathrm{C} \pm 0.6^{\circ} \mathrm{C}$, $1.4^{\circ} \mathrm{C} \pm 0.4^{\circ} \mathrm{C}$, and $0.9^{\circ} \mathrm{C} \pm 0.1^{\circ} \mathrm{C}$, respectively (Table $\mathrm{S} 4$ ). These results show that increasing irradiance results in increased $\mathrm{CO}$ elimination during a single pass through the device and that the blood temperature increase caused by the highest level of irradiance (at each blood flow rate tested) was below that which might cause adverse effects, such as protein denaturation. ${ }^{24}$

\section{Effect of changes in blood flow rate on $\mathrm{COHb}$ - $t_{1 / 2}$}

To assess whether the efficacy of CO removal is altered by changes in the blood flow rate, the COHb- $t_{1 / 2}$ was determined at blood flows ranging from 80 to $240 \mathrm{ml} / \mathrm{min}$ (Figure 1B). When treating $300 \mathrm{ml}$ of human whole blood at a $\mathrm{Hb}$ concentration of $9.9 \pm 0.7 \mathrm{~g} / \mathrm{dl}$ with $100 \% \mathrm{O}_{2}$ and phototherapy, an increase in blood flow rate from $80 \mathrm{ml} / \mathrm{min}$ to either 160 or $240 \mathrm{ml} / \mathrm{min}$ reduced the $\mathrm{COHb}-t_{1 / 2}$ from $21.4 \pm 1.4 \mathrm{~min}$ to $19.4 \pm 0.8 \mathrm{~min}$ and from $21.4 \pm 1.4 \mathrm{~min}$ to $14.6 \pm 0.7 \mathrm{~min} \quad(p<0.001)$ respectively (Figure $4 \mathrm{~A}$ and Table S5). A further increase in blood flow rate from 160 to $240 \mathrm{ml} / \mathrm{min}$ reduced the $\mathrm{COHb}-t_{1 / 2}$ from $19.4 \pm 0.8 \mathrm{~min}$ to $14.6 \pm 0.7 \mathrm{~min}(p<0.001)$. The quantity of $\mathrm{CO}$ eliminated by the photo-ECMO device (effluent $\mathrm{CO}$ ) during phototherapy was greater at a blood flow rate of $240 \mathrm{ml} / \mathrm{min}$ compared to either $80 \mathrm{ml} / \mathrm{min}$ or $160 \mathrm{ml} / \mathrm{min}$ (Figure 4B). The quantity of $\mathrm{CO}$ eliminated by the photo-ECMO device (effluent $\mathrm{CO}$ ) was also greater during ventilation with $100 \% \mathrm{O}_{2}$ combined with phototherapy at each blood flow rate when compared to oxygen only (without phototherapy) at the same blood flow rate (Figure S3). These results show that the maxi photo-ECMO device is effective over a range of blood flow rates and, that when used with higher blood flow rates, more $\mathrm{CO}$ is eliminated.

\section{In vitro studies to assess the ability of the photo- ECMO system to remove $\mathrm{CO}$ from human blood}

We hypothesized that assembling multiple maxi photoECMO devices in parallel, to create a "photo-ECMO system" (Figure S4) would be required to further increase the $\mathrm{CO}$ elimination rate. By increasing the number of devices, the total volume of blood that could be treated in a given amount of time would increase. To investigate whether the photo-ECMO system, consisting of six maxi photo-ECMO devices in parallel, further increases the $\mathrm{CO}$ elimination rate, the $\mathrm{COHb}-t_{1 / 2}$ was determined in an in vitro circuit containing $1 \mathrm{~L}$ of $\mathrm{CO}$-poisoned human blood $(\mathrm{COHb}$ level of $90 \%$ ) at a $\mathrm{Hb}$ concentration of $10.0 \pm 1.4 \mathrm{~g} / \mathrm{dl}$ (Figures 1B and $5 \mathrm{~A}$ ). Compared to a single maxi photo-ECMO device with a blood flow rate of $92 \mathrm{ml} / \mathrm{min}$, the photo-ECMO system (blood flow rate of $550 \mathrm{ml} / \mathrm{min}$ ) reduced the 


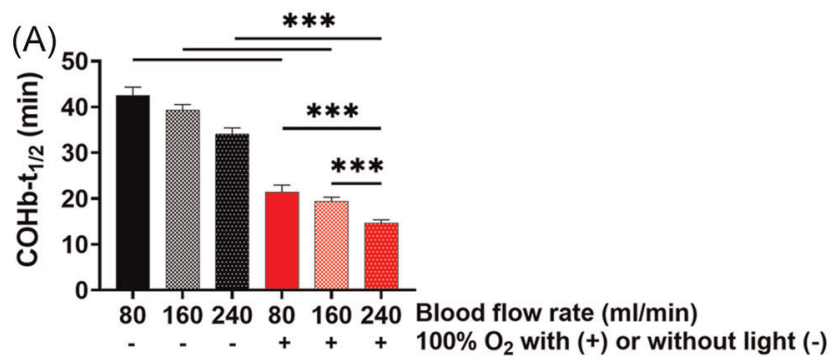

(B)

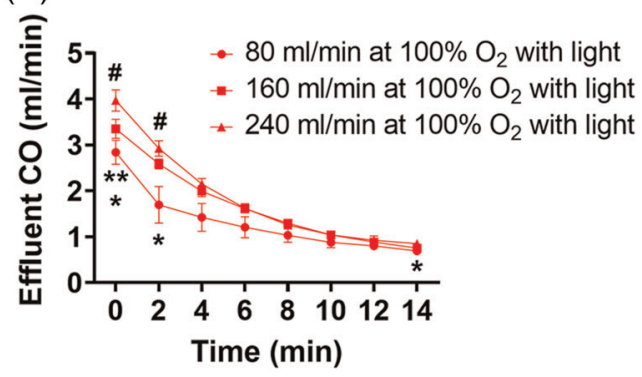

F I G URE 4 Effect of different blood flow rates on COHb- $t_{1 / 2}$ and effluent $\mathrm{CO}$ using the photo-ECMO device. (A) The effect of different blood flow rates on the $\mathrm{COHb}-\mathrm{t}_{1 / 2}$ during treatment of blood with $100 \%$ $\mathrm{O}_{2}$ alone (black bars) or with $100 \% \mathrm{O}_{2}$ and red phototherapy (red bars) are shown $\left(N=4\right.$ per group). ${ }^{* * *} p<0.001$, one-way ANOVA. Blood volume was $300 \mathrm{ml}$; $\mathrm{Hb}$ concentration was $9.9 \pm 0.7 \mathrm{~g} / \mathrm{dl}$; blood flow rate was 80,160 , and $240 \mathrm{ml} / \mathrm{min}$; gas flow rate was $1,1.6$, and $2.4 \mathrm{~L} /$ min. Blood temperature was $37^{\circ} \mathrm{C}$. All data represent mean $\pm \mathrm{SD}$. (B) The effect of different blood flow rates on the quantity of $\mathrm{CO}$ eliminated by the photo-ECMO device (effluent $\mathrm{CO}$ ) during treatment of blood with $100 \% \mathrm{O}_{2}$ and red light at $623 \mathrm{~nm}(N=4$ per group). ${ }^{* *} p<0.01$ at 80 versus $160 \mathrm{ml} / \mathrm{min}$ and $* p<0.05$ at 80 versus $240 \mathrm{ml} /$ min; ${ }^{\#} p<0.05$ at 160 versus $240 \mathrm{ml} / \mathrm{min}$, two-way ANOVA. All data represent mean $\pm \mathrm{SD}$. ANOVA, analysis of variance; $\mathrm{COHb}-t_{1 / 2}$, halflife of carboxyhemoglobin; ECMO, extracorporeal membrane oxygenation

COHb- $t_{1 / 2}$ from $69.0 \pm 2.1 \mathrm{~min}$ to $19.2 \pm 4.7 \mathrm{~min}$ during ventilation with $100 \% \mathrm{O}_{2}$. When red light was applied to each device, under the same oxygen and blood flow rate conditions, the $\mathrm{COHb}-t_{1 / 2}$ decreased to $34.8 \pm 2.4 \mathrm{~min}$ (single maxi photo-ECMO device) and $6.3 \pm 1.2 \mathrm{~min}$ (photoECMO system) (Figure 5B and Table S6). The quantity of $\mathrm{CO}$ eliminated by the photo-ECMO system (effluent $\mathrm{CO}$ ) was greater compared to a single maxi photo-ECMO device with or without light (Figure 5C). These results show that in this in vitro system, the photo-ECMO system removes $\mathrm{CO}$ faster from CO-poisoned blood than a single maxi photoECMO device.

\section{Elimination of $\mathrm{CO}$ from a 45-kg CO-poisoned pig using the photo-ECMO system}

To investigate the ability of the photo-ECMO system to remove $\mathrm{CO}$ from blood in vivo, we tested the device in a porcine model of $\mathrm{CO}$ poisoning with an initial $\mathrm{COHb}$ level of $53.3 \% \pm 2.5 \%$. The $\mathrm{COHb}-t_{1 / 2}$ was $21.6 \pm 2.6 \mathrm{~min}$ when animals breathed $100 \% \mathrm{O}_{2}$ through the endotracheal tube,
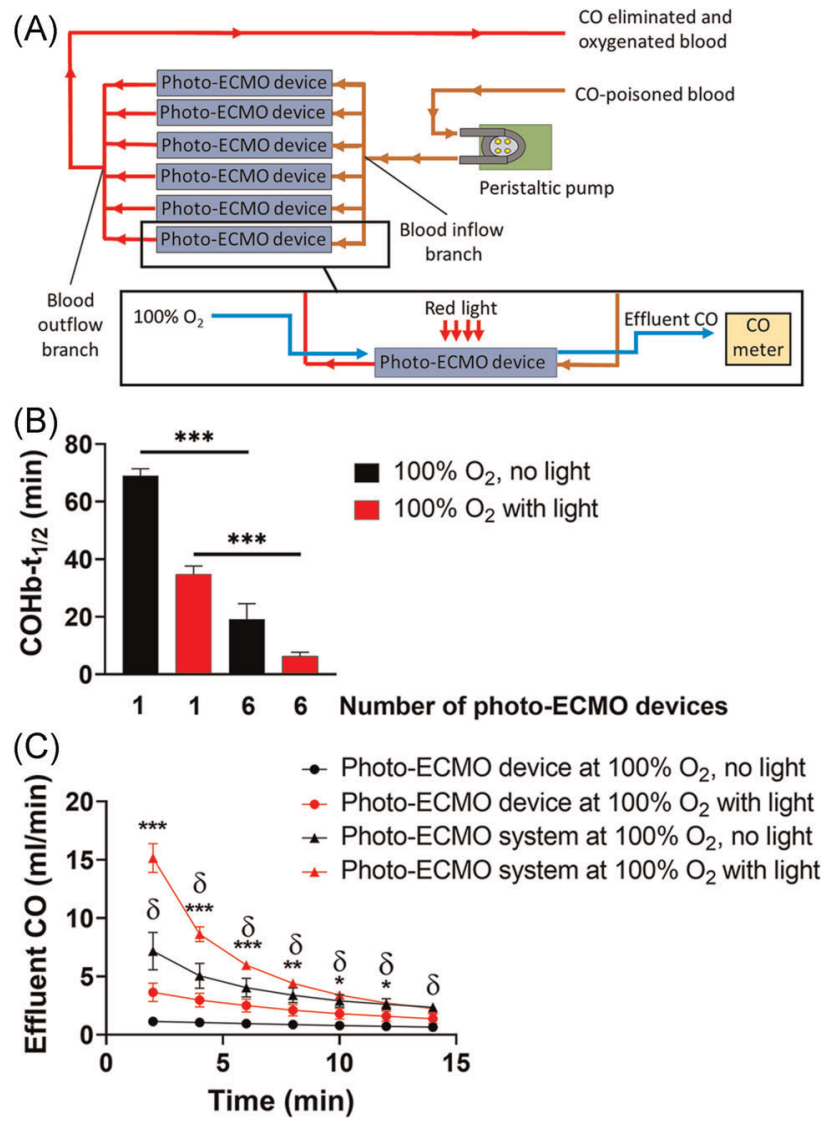

F I G URE 5 Photo-ECMO system and in vitro CO elimination including six identical photo-ECMO devices (photo-ECMO system). (A) Depiction of the photo-ECMO system. The photo-ECMO system consisted of six maxi photo-ECMO devices connected in parallel. A peristaltic pump was used to propel CO-poisoned blood into the photoECMO system. Blood exited the photo-ECMO system through a blood outflow branch. Each photo-ECMO device was either ventilated with $100 \% \mathrm{O}_{2}$ alone at a gas flow rate of $1 \mathrm{~L} / \mathrm{min}$ or additionally exposed to red light at $623 \mathrm{~nm}$ while blood circulated through the photo-ECMO system. $\mathrm{CO}$ exiting the photo-ECMO system (effluent $\mathrm{CO}$ ) was measured using a $\mathrm{CO}$ meter. (B) $\mathrm{COHb}-t_{1 / 2}$ during treatment with one photo-ECMO device and the photo-ECMO system. Blood volume was $1 \mathrm{~L}$; $\mathrm{Hb}$ concentration was $10.0 \pm 1.4 \mathrm{~g} / \mathrm{dl}$; total blood flow rate of one photo-ECMO device was $92 \mathrm{ml} / \mathrm{min}$; total blood flow rate of the photoECMO system was $550 \mathrm{ml} / \mathrm{min}$, total gas flow rate for one photoECMO device was $1 \mathrm{~L} / \mathrm{min}$; total gas flow rate for the photo-ECMO system was $6 \mathrm{~L} / \mathrm{min}(1 \mathrm{~L} / \mathrm{min}$ per photo-ECMO device) $(N=4$ per group). Blood temperature was $37^{\circ} \mathrm{C} .{ }^{* * *} p<0.001$, one-way ANOVA. All data represent mean $\pm \mathrm{SD}$. (C) The quantity of $\mathrm{CO}$ eliminated from the photo-ECMO device and photo-ECMO system (effluent $\mathrm{CO}$ ) during treatment with $100 \% \mathrm{O}_{2}$ alone or ventilation with $100 \% \mathrm{O}_{2}$ and illumination with red light at $623 \mathrm{~nm}(N=4$ per group $) . * * * p<0.001$, $* * p<0.005$, and $* p<0.05$ one photo-ECMO device versus photoECMO system during treatment of blood with $100 \% \mathrm{O}_{2}$ and red light. ${ }^{\delta} p<0.05$ one photo-ECMO device versus photo-ECMO system during ventilation with $100 \% \mathrm{O}_{2}$ alone, two-way ANOVA. All data represent mean $\pm \mathrm{SD}$. ANOVA, analysis of variance; $\mathrm{COHb}-t_{1 / 2}$, half-life of carboxyhemoglobin; ECMO, extracorporeal membrane oxygenation

before being connected to the photo-ECMO system (control) (Figure 6A and Table S7). After the animals were connected to the photo-ECMO device system, the blood flow rate through the device was set $550 \mathrm{ml} / \mathrm{min}$ and the 

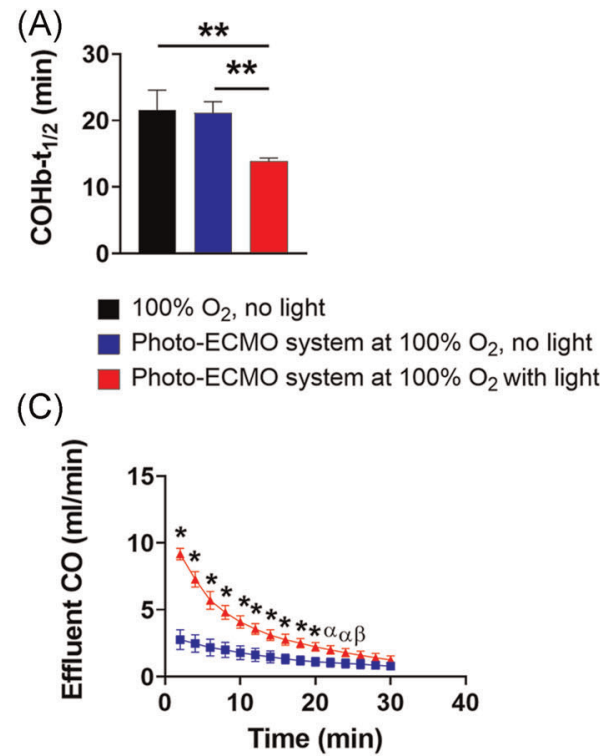
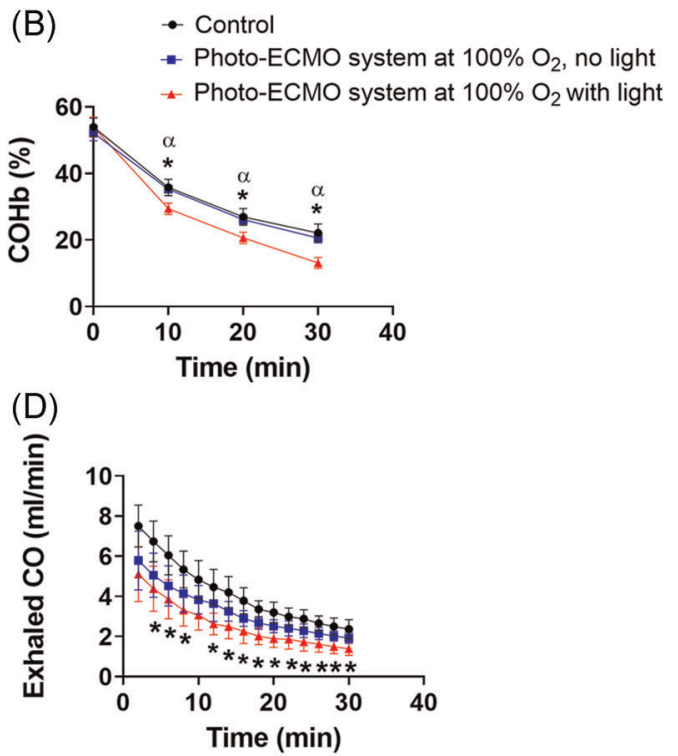

F I G URE 6 Effect of extracorporeal CO removal with the photo-ECMO system on the rate of CO elimination in CO-poisoned pigs. (A) Calculated COHb- $t_{1 / 2}$ during treatment. ${ }^{* *} p=0.001$ control and photo-ECMO system without light versus photo-ECMO system with light, one-way ANOVA. All data represent mean \pm SD. $N=4$ animals in total with each group being tested once in each animal. (B) Variation in arterial $\mathrm{COHb}$ over time. ${ }^{*} p<0.05$ control versus photo-ECMO system with light. ${ }^{\alpha} p<0.05$ photo-ECMO system without light versus photo-ECMO system with light, two-way ANOVA. All data represent mean \pm SD. (C) The quantity of CO eliminated from the photo-ECMO system (effluent CO). ${ }^{*} p<0.001 ;{ }^{\alpha} p<0.01$, and ${ }^{\beta} p<0.05$ versus photo-ECMO system without light, two-way ANOVA. All data represent mean \pm SD. (D) Exhaled CO from the animal. ${ }^{*} p<0.05$ control versus photo-ECMO system with light, two-way ANOVA. All data represent mean \pm SD. ANOVA, analysis of variance; $\mathrm{COHb}$, carboxyhemoglobin; ECMO, extracorporeal membrane oxygenation
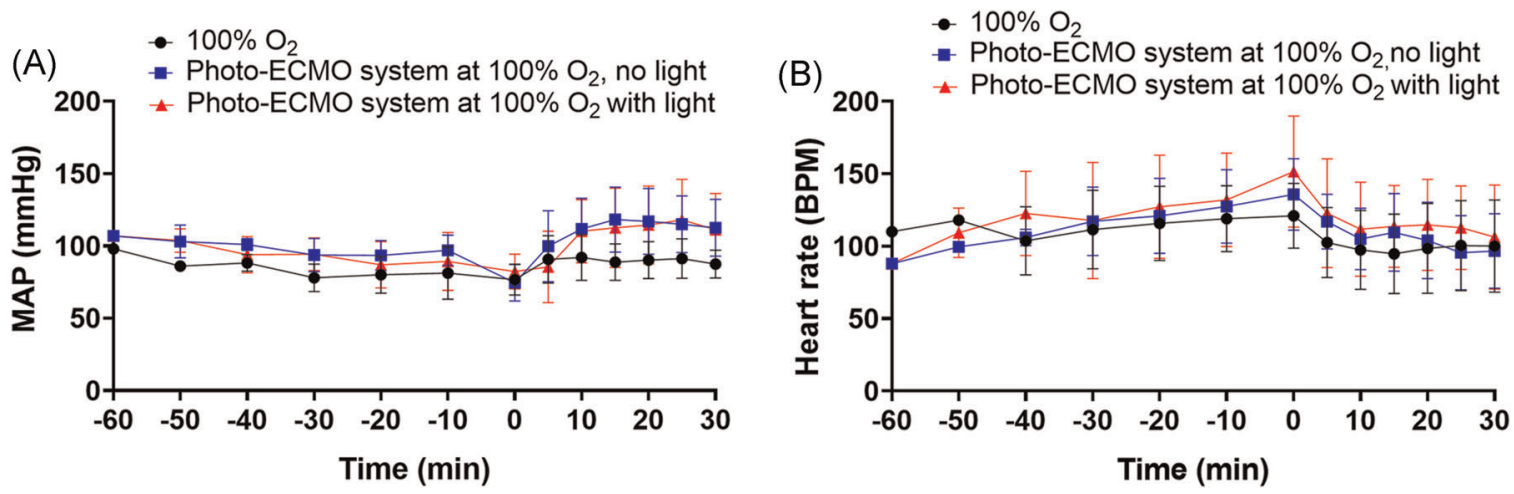

F I G URE 7 Hemodynamic parameters in a pig model of $\mathrm{CO}$ poisoning during $\mathrm{CO}$ poisoning and during treatment with $100 \% \mathrm{O}_{2}$ alone or after being connected to the photo-ECMO system with and without exposition to light. (A) Mean arterial pressure (MAP) and (B) Heart rate (HR). Two-way ANOVA was carried out from time point -30 to $30 \mathrm{~min}$ (missing values before time point -30 min due to variable duration of CO poisoning). $p=$ not significant in between groups. All data represent mean \pm SD. $N=4$ animals in total with each group being tested once in each animal. $\mathrm{COHb}$, carboxyhemoglobin; ECMO, extracorporeal membrane oxygenation

device was either ventilated with $100 \% \mathrm{O}_{2}$ (without light) or with $100 \% \mathrm{O}_{2}$ while being exposed to red light (phototherapy). When the photo-ECMO system was ventilated with $100 \% \mathrm{O}_{2}$ but not exposed to red light, the $\mathrm{COHb}-t_{1 / 2}$ was unchanged $(21.1 \pm 1.5 \mathrm{~min}$ vs. $21.6 \pm 2.6 \mathrm{~min})$. Addition of phototherapy to the photo-ECMO system decreased the $\mathrm{COHb}$ half-life by $36 \%$ compared to control $(13.9 \pm 0.4 \mathrm{~min}$ vs. $21.6 \pm 2.6 \mathrm{~min})(p=0.001)$. During the 30 -min treatment period, the arterial $\mathrm{COHb}$ decreased from $53.9 \% \pm 2.6 \%$ to $13.1 \% \pm 1.4 \%$ in animals treated with the photo-ECMO system exposed to red light. In contrast, in animals treated with $100 \% \mathrm{O}_{2}$ through the endotracheal tube alone (control), the arterial $\mathrm{COHb}$ decreased from $54.0 \% \pm 2.3 \%$ to $22.1 \% \pm 2.4 \%$ (Figure $6 \mathrm{~B}$ ). The quantity of $\mathrm{CO}$ eliminated by the photo-ECMO system (effluent $\mathrm{CO}$ ) was greater when the system was exposed to light compared to ventilation with $100 \% \mathrm{O}_{2}$ alone (Figure 6C). Pigs in the control group (breathing $100 \% \mathrm{O}_{2}$ through the endotracheal tube alone) exhaled more $\mathrm{CO}$ from the lungs compared to pigs treated with the photo-ECMO system with light. This result was 
expected because the remaining $\mathrm{COHb}$ concentration in the blood of pigs in the control group was higher at each time point (Figure 6D). The body temperature of the pig increased by $1.2^{\circ} \mathrm{C} \pm 0.2^{\circ} \mathrm{C}$ when the photo-ECMO system was exposed to light. During treatment with the photoECMO system, the plasma-free $\mathrm{Hb}$ concentration increased but was steadily below $100 \mathrm{mg} / \mathrm{dl}$ (Figure S5). There was no difference in hemodynamics between the treatment groups (Figure 7). Taken together, the results show that the photoECMO system increases the rate of $\mathrm{CO}$ elimination in vivo, without significantly increasing the animal's body temperature or causing hemodynamic instability.

\section{DISCUSSION}

In this study, we developed and tested a photo-ECMO system designed to treat patients with $\mathrm{CO}$ poisoning. The system is composed of six "maxi" photo-ECMO devices, each consisting of 15 polypropylene membrane layers and four openings for blood and gas inlets and outlets. Compared with the previously described "mini" photoECMO device, ${ }^{23}$ the illumination area and the blood compartment volume were increased 6- and 15-fold, respectively. The illumination and gas exchange areas were increased 6- and 12-fold, respectively. Each of the maxi photo-ECMO devices was able to completely oxygenate blood in a single pass through the device. Ventilation of the device with $100 \% \mathrm{O}_{2}$ and exposure to red light increased the rate of $\mathrm{CO}$ elimination compared to ventilation with $100 \% \mathrm{O}_{2}$ alone. The rate of $\mathrm{CO}$ elimination was constant over a broad range of gas flow rates while increased blood flow rates (over the range tested) enhanced $\mathrm{CO}$ elimination. Increases in the intensity of light also increased $\mathrm{CO}$ elimination, without significantly increasing blood temperature. In vitro, when the photoECMO system was ventilated with $100 \% \mathrm{O}_{2}$ and illuminated with red light, the COHb- $t_{1 / 2}$ in blood decreased by almost $70 \%$, from 19.2 to $6.3 \mathrm{~min}$ compared to ventilation with $100 \% \mathrm{O}_{2}$ alone. Treatment of CO-poisoned pigs with the photo-ECMO system (with additional light exposure) increased CO elimination by $36 \%$.

The most basic requirement for a photo-ECMO device for the treatment of $\mathrm{CO}$ poisoning is the ability to oxygenate circulating blood. The normal oxygen consumption in a resting individual is $250 \mathrm{ml} / \mathrm{min}$ at a cardiac output of $5 \mathrm{~L} /$ min. ${ }^{25}$ Thus, the membrane oxygenator must provide at least $50 \mathrm{ml} \mathrm{O}_{2}$ per $\mathrm{L}$ blood flow to meet the minimum oxygen requirement. ${ }^{26} \mathrm{We}$ showed that the photo-ECMO device fulfilled this requirement with an average oxygen delivery of $112 \mathrm{ml} \mathrm{O}_{2}$ per L blood flow. In addition, a high blood $\mathrm{PO}_{2}$ level accelerates $\mathrm{CO}$ elimination. ${ }^{19}$ In humans with healthy lungs, the arterial $\mathrm{O}_{2}$ partial pressure increases from 100 to $600 \mathrm{mmHg}$ when breathing $100 \% \mathrm{O}_{2}$ instead of $21 \% \mathrm{O}_{2}{ }^{27}$ Commercially available membrane oxygenators reach post-membrane $\mathrm{PO}_{2}$ levels of $400-500 \mathrm{mmHg}{ }^{28}$ In comparison, our photo-ECMO device showed similar post-membrane $\mathrm{PO}_{2}$ levels, demonstrating an oxygenating performance equivalent to commercial devices.

The application of extracorporeal blood phototherapy to treat $\mathrm{CO}$ poisoning in a large animal requires additional, special design considerations. The blood compartment needs to be thin, so as to enable light penetration, and the illumination area has to be as large as possible to facilitate the exposure of blood to light. Commercially available membrane oxygenators are not suitable for phototherapy, because their blood compartment is too thick, thereby limiting light penetration. Compared to commercially available membrane oxygenators, the blood compartment of the photo-ECMO device is one-third as thick and the illumination area is almost three-fold greater. ${ }^{29}$

We found that $\mathrm{CO}$ elimination is efficient at a blood flow rate of $550 \mathrm{ml} / \mathrm{min}$, which corresponds to $5 \%-12 \%$ of a pig's cardiac output. ${ }^{30}$ Because this relatively low blood flow rate is sufficient to achieve adequate $\mathrm{CO}$ removal, the photo-ECMO system can be used with relatively small catheters, which could be placed by paramedics into a patient at the site of $\mathrm{CO}$ poisoning, rather than requiring placement in the emergency room or ICU.

CO-poisoned patients often suffer from acute lung injury caused by the inhalation of different toxic components in smoke (e.g., $\mathrm{NO}_{2}$, hydrogen chloride) as well as by thermal injuries from the inhalation of hot gases. ${ }^{20,21,31-34}$ Treatment of these patients with inhaled $100 \% \mathrm{O}_{2}$ has a relatively little benefit because of decreased gas exchange in the damaged lungs. We anticipate that the use of the photo-ECMO device will be especially beneficial for these patients.

Hemolysis is associated with increased morbidity and mortality due to impaired renal function. ${ }^{35}$ While using the photo-ECMO device in pigs, the concentration of free $\mathrm{Hb}$ increased at the beginning of treatment but remained below $100 \mathrm{mg} / \mathrm{dl}$ until the end of the treatment. We anticipate that in CO-poisoned patients, the photo-ECMO system will only be required for a short time, thereby limiting the patient's exposure to free $\mathrm{Hb}$.

This study has some limitations. The photo-ECMO device was not directly compared to other novel approaches to treat $\mathrm{CO}$ poisoning. These include neuroglobin ${ }^{36}$ and hemoCD, ${ }^{37}$ both high-affinity $\mathrm{CO}$ scavengers, as well as hydroxocobalamin, ${ }^{38}$ which metabolizes $\mathrm{CO}$ to $\mathrm{CO}_{2}$. Because these therapies increase $\mathrm{CO}$ elimination through different mechanisms, a combination of these treatments with photo-ECMO could possibly facilitate $\mathrm{CO}$ removal in $\mathrm{CO}$-poisoned patients. Further studies are needed to assess and to compare combinations of these therapies. A second limitation of this study is that we did not directly compare treatment using the photo-ECMO device to HBO therapy. However, we anticipate that these two approaches will have different applications and advantages. In contrast to the proposed photo-ECMO therapy, treatment with $\mathrm{HBO}$ requires transporting the patient to specialized treatment. In addition, in patients with severe acute lung injury, $\mathrm{HBO}$ will be less effective because of decreased gas 
exchange in the lung. ${ }^{18}$ Contrarily, extracorporeal blood phototherapy might be applied immediately after $\mathrm{CO}$ poisoning.

In summary, we developed a veno-venous extracorporeal photo-ECMO system and demonstrated its feasibility and effectiveness for the elimination of $\mathrm{CO}$ from $45 \mathrm{~kg}$ pigs with $\mathrm{CO}$ poisoning. Future modifications of the photo-ECMO system will be directed at making the device more compact and portable so as to permit treatment of CO-poisoned patients at the scene of their poisoning, during transit to a local emergency room, and in hospitals that lack HBO facilities.

\section{ACKNOWLEDGMENTS}

This study was supported by funds from the Anesthesia Center for Critical Care Research of the Department of Anesthesia, Critical Care, and Pain Medicine and the Wellman Center for Photomedicine (Massachusetts General Hospital, Harvard Medical School). Donald B. Bloch was supported by Luisa Hunnewell and Larry Newman. Anna Fischbac, Steffen B. Wiegand, and Lisa Traeger are supported by the German Research Foundation (DFG) [FI 2429/1-1, WI 5162/2-1, TR 1642/1-1].

\section{CONFLICT OF INTERESTS}

Warren M. Zapol, R. Rox Anderson, Walfre Franco, William A. Farinelli, Luca Zazzeron, and Anna Fischbach are listed as inventors on a patent application submitted by the Massachusetts General Hospital on the technology described in this paper (System and method for extracorporeal carbon monoxide removal with phototherapy).

\section{AUTHOR CONTRIBUTIONS}

Conceptualization: Anna Fischbach, Aranya Bagchi, R. Rox Anderson, and Warren M. Zapol. Methodology: Anna Fischbach, Steffen B. Wiegand, Luca Zazzeron, and Lisa Traeger. Investigation: Anna Fischbach, Steffen B. Wiegand, Luca Zazzeron, Lisa Traeger, Raffaele di Fenza, Luigi Grassi, William A. Farinelli, Walfre Franco, and Sandeep Korupolu. Funding acquisition and Project administration: Anna Fischbach and Warren M. Zapol. Supervision: Warren M. Zapol and R. Rox Anderson. Writing original draft: Anna Fischbach, Donald B. Bloch, R. Rox Anderson, and Warren M. Zapol. Writing - review and editing: Anna Fischbach, Steffen B. Wiegand, Luca Zazzeron, Lisa Traeger, Raffaele di Fenza, Aranya Bagchi, William A. Farinelli, Walfre Franco, Sandeep Korupolu, Jutta Arens, Luigi Grassi, Francesco Zadek, Donald B. Bloch, R. Rox Anderson, and Warren M. Zapol.

\section{DATA AVAILABILITY STATEMENT}

The photo-ECMO device is not commercially available but is available at cost via material transfer agreement (contact Warren M. Zapol). All the data used for the manuscript are present in the main text and/or in the Supporting Information Materials.

\section{OR CID}

Anna Fischbach (1) http://orcid.org/0000-0003-4997-428X Walfre Franco (D) http://orcid.org/0000-0003-0905-4083

\section{REFERENCES}

1. Hampson NB, Weaver LK. Carbon monoxide poisoning: a new incidence for an old disease. Undersea Hyperb Med. 2007;34(3): $163-8$.

2. Thom SR. Hyperbaric-oxygen therapy for acute carbon monoxide poisoning. N Engl J Med. 2002;347(14):1105-06. https://doi.org/ 10.1056/NEJMe020103

3. Hampson NB, Hauff NM. Risk factors for short-term mortality from carbon monoxide poisoning treated with hyperbaric oxygen. Crit Care Med. 2008;36(9):2523-7. https://doi.org/10.1097/CCM. 0b013e31818419d8

4. Hardy KR, Thom SR. Pathophysiology and treatment of carbon monoxide poisoning. Clin Toxicol. 1994;32(6):613-29. https://doi. org/10.3109/15563659409017973

5. Tibbles PM, Perrotta PL. Treatment of carbon monoxide poisoning: a critical review of human outcome studies comparing normobaric oxygen with hyperbaric oxygen. Ann Emerg Med. 1994;24(2):269-76. https://doi.org/10.1016/S0196-0644(94)70141-5

6. Hampson NB, Piantadosi CA, Thom SR, Weaver LK. Practice recommendations in the diagnosis, management, and prevention of carbon monoxide poisoning. Am J Respir Crit Care Med. 2012; 186(11):1095-101. https://doi.org/10.1164/rccm.201207-1284CI

7. Kaya H, Coşkun A, Beton O, Zorlu A, Kurt R, Yucel H, et al. $\mathrm{COHgb}$ levels predict the long-term development of acute myocardial infarction in CO poisoning. Am J Emerg Med. 2016;34(5): 840-4. https://doi.org/10.1016/j.ajem.2016.01.036

8. Satran D, Henry CR, Adkinson C, Nicholson CI, Bracha Y, Henry TD. Cardiovascular manifestations of moderate to severe carbon monoxide poisoning. J Am Coll Cardiol. 2005;45(9): 1513-6. https://doi.org/10.1016/j.jacc.2005.01.044

9. Andre L, Boissière J, Reboul C, Perrier R, Zalvidea S, Meyer G, et al. Carbon monoxide pollution promotes cardiac remodeling and ventricular arrhythmia in healthy rats. Am J Respir Crit Care Med. 2010;181(6):587-95. https://doi.org/10.1164/rccm.200905-0794OC

10. Dziewierz A, Ciszowski K, Gawlikowski T, Rakowski T, Kleczyński P, Surdacki A, et al. Primary angioplasty in patient with ST-segment elevation myocardial infarction in the setting of intentional carbon monoxide poisoning. J Emerg Med. 2013; 45(6):831-834. https://doi.org/10.1016/j.jemermed.2013.05.061

11. Hampson NB. Cost of accidental carbon monoxide poisoning: a preventable expense. Prev Med Rep. 2016;3:21-4. https://doi.org/ 10.1016/j.pmedr.2015.11.010

12. Lo Iacono L, Boczkowski J, Zini R, Salouage I, Berdeaux A, Motterlini R, et al. A carbon monoxide-releasing molecule (CORM-3) uncouples mitochondrial respiration and modulates the production of reactive oxygen species. Free Radic Biol Med. 2011;50(11):1556-64. https://doi.org/10.1016/j.freeradbiomed.2011.02.033

13. Hall JE. Textbook of Medical Physiology. Philadelphia, PA: Saunders/Elsevier; 2010.

14. Haldane J. The action of carbonic oxide on man. J Physiol. 1895; 18(5-6):430-62. https://doi.org/10.1113/jphysiol.1895.sp000578

15. Weaver LK, Hopkins RO, Chan KJ, Churchill S, Elliott CG, Clemmer TP, et al. Hyperbaric oxygen for acute carbon monoxide poisoning. N Engl J Med. 2002;347(14):1057-67. https://doi.org/ 10.1056/NEJMoa013121

16. Weaver LK. Hyperbaric oxygen in carbon monoxide poisoning. Br Med J. 1999;319(7217):1083-4. https://doi.org/10.1136/bmj.319. 7217.1083

17. Peterson JE. Postexposure relationship of carbon monoxide in blood and expired air. Arch Environ Health. 1970;21(2):172-3. https://doi.org/10.1080/00039896.1970.10667216

18. Weaver LK, Deru K. Carboxyhemoglobin half-life during hyperbaric oxygen in a patient with lung dysfunction: a case report. 
Undersea Hyperb Med. 2017;44(2):173-7. https://doi.org/10 22462/3.4.2017.12

19. Pace N, Strajman EWEL. Acceleration of carbon monoxide elimination in man by high pressure oxygen. Science. 1950;111:652-4.

20. Yang CC, Ger J, Li CF. Formic acid: a rare but deadly source of carbon monoxide poisoning. Clin Toxicol. 2008;46(4):287-9. https://doi.org/10.1080/15563650701378746

21. Schneir A, Rentmeester L. Carbon monoxide poisoning and pulmonary injury from the mixture of formic and sulfuric acids. Clin Toxicol. 2016;54(5):450-3. https://doi.org/10.3109/15563650.2016. 1157723

22. Haldane J, Smith JL. The oxygen tension of arterial blood. J Physiol. 1896;20(6):497-520. https://doi.org/10.1113/jphysiol.1896.sp000634

23. Zazzeron L, Fischbach A, Franco W, Farinelli WA, Ichinose F, Bloch DB, et al. Phototherapy and extracorporeal membrane oxygenation facilitate removal of carbon monoxide in rats. Sci Transl Med. 2019;11(513):eaau4217. https://doi.org/10.1126/scitranslmed.aau4217

24. Vazquez RLD. Plasma protein denaturation with graded heat exposure. Perfusion. 2013;28:557-9.

25. Lumb AB Nunn's Applied respiratory physiology. 5th, Oxford, United Kingdom: Butterworth Heinemann; 2000:285-286.

26. Smithline HA, Ward KR, Chiulli DA, Blake HC, Rivers EP. Whole body oxygen consumption and critical oxygen delivery in response to prolonged and severe carbon monoxide poisoning. Resuscitation. 2003;56(1):97-104. https://doi.org/10. 1016/S0300-9572(02)00272-1

27. Sharma S \& Hashmi MF Partial pressure of oxygen (PO2). StatPearls Publishing; Treasure Island (FL) 2018. Available from: http://www.ncbi.nlm.nih.gov/pubmed/29630271

28. Rambaud J, Guilbert J, Guellec I, Renolleau S. A pilot study comparing two polymethylpentene extracorporeal membrane oxygenators. Perfusion. 2013;28(1):14-20. https://doi.org/10.1177/ 0267659112457970

29. Jabur GNS, Sidhu K, Willcox TW, Mitchell SJ. Clinical evaluation of emboli removal by integrated versus non-integrated arterial filters in new generation oxygenators. Perfusion (United Kingdom). 2016;31(5):409-17. https://doi.org/10.1177/0267659115621614

30. Bruce RM, Crockett DC, Morgan A, Tran MC, Formenti F, Phan PA, et al. Noninvasive cardiac output monitoring in a porcine model using the inspired sinewave technique: a proof-ofconcept study. Br J Anaesth. 2019;123(2):126-34. https://doi.org/ 10.1016/j.bja.2019.02.025

31. Dries DJ, Endorf FW. Inhalation injury: epidemiology, pathology, treatment strategies. Scand J Trauma Resusc Emerg Med. 2013;21(1):e31. https://doi.org/10.1186/1757-7241-21-31
32. Rehberg S, Maybauer MO, Enkhbaatar P, Maybauer DM, Yamamoto Y, Traber DL. Pathophysiology, management and treatment of smoke inhalation injury. Expert Rev Respir Med. 2009;3(3):283-97. https://doi.org/10.1586/ERS.09.21

33. Weiss SM, Lakshminarayan S. Acute inhalation injury. Clin Chest Med. 1994;15(1):103-16. https://doi.org/10.5152/eajm.2010.09

34. Fein A, Grossman RF, Jones JG, Hoeffel J, McKay D. Carbon monoxide effect on alveolar epithelial permeability. Chest. 1980; 78(5):726-31. https://doi.org/10.1378/chest.78.5.726

35. Dufour N, Radjou A, Thuong M. Hemolysis and plasma free hemoglobin during extracorporeal membrane oxygenation support: from clinical implications to laboratory details. ASAIO J. 2020; 66(3):239-46. https://doi.org/10.1097/MAT.0000000000000974

36. Rose JJ, Bocian KA, Xu Q, Wang L, DeMartino AW, Chen X, et al. A neuroglobin-based high-affinity ligand trap reverses carbon monoxide-induced mitochondrial poisoning. J Biol Chem. 2020;295(19):6357-71. https://doi.org/10.1074/jbc.RA119.010593

37. Kitagishi H, Negi S, Kiriyama A, Honbo A, Sugiura Y, Kawaguchi AT, et al. A diatomic molecule receptor that removes $\mathrm{CO}$ in a living organism. Angew Chemie Int Ed. 2010;49(7): 1312-5. https://doi.org/10.1002/anie.200906149

38. Roderique JD, Josef CS, Newcomb AH, Reynolds PS, Somera LG, Spiess BD. Preclinical evaluation of injectable reduced hydroxocobalamin as an antidote to acute carbon monoxide poisoning. J Trauma Acute Care Surg. 2015;79(4):S116-20. https://doi.org/10. 1097/TA.0000000000000740

\section{SUPPORTING INFORMATION}

Additional Supporting Information may be found online in the supporting information tab for this article.

How to cite this article: Fischbach A, Wiegand SB, Zazzeron L, Traeger L, di Fenza R, Bagchi A, et al. Veno-venous extracorporeal blood phototherapy increases the rate of carbon monoxide (CO) elimination in CO-poisoned pigs. Lasers Surg Med. 2021;1-12. https://doi.org/10.1002/1sm.23462 